\title{
GROWTH AND CHARACTERISATION OF PULSED-LASER DEPOSITED TIN THIN FILMS ON CUBE-TEXTURED COPPER AT DIFFERENT TEMPERATURES
}

\begin{abstract}
High-quality titanium nitride thin films have been grown on a cube-textured copper surface via pulsed laser deposition. The growth of TiN thin films has been very sensitive to pre-treatment procedure and substrate temperature. It is difficult to grow heteroexpitaxial TiN films directly on copper tape due to large differences in lattice constants, thermal expansion coefficients of the two materials as well as polycrystalline structure of substrate. The X-Ray diffraction measurement revealed presence of high peaks belonged to TiN(200) and TiN(111) thin films, depending on used etcher of copper surface. The electron diffraction patterns of TiN(200)/Cu films confirmed the single-crystal nature of the films with cube-on-cube epitaxy. The high-resolution microscopy on our films revealed sharp interfaces between copper and titanium nitride with no presence of interfacial reaction.

Keywords: Thin films, Coated conductors, Deposition, PLD, Microstructure
\end{abstract}

\section{Introduction}

For many technologies, the integration of materials which are chemically incompatible is meaningful task, due to existence of destructive interfacial reactions or negative contamination. Sometimes, such integration should simplified transfer of novel thin films to other substrates after the cost-effective wet etching of chemical active interface. In case of pure copper, applications where such chemical barrier are needed to separate the metal from other materials contain semiconductor interconnects [1-3], coated high-temperature superconducting tapes [4-10] and CVDgrown graphene [11,12]

Since 1996, the developing of barrier layers as well as the complex heterostructures for metals has especially began important for high-temperature superconducting tapes based on epitaxial superconducting films on flexible biaxially textured substrates [13]. In high-temperature superconductors, the superconducting critical current density in thin films can be limited by the presence of large angle grain boundaries [14]. Fortunately, in Rolling-Assisted Biaxially Textured Substrates (RABiTS) technology this structural defect could be eliminated through epitaxial growth of buffer and superconducting films onto flexible tape. Moreover, those tapes are crystallographically textured during thermo-mechanical processing [15]. The development of a superconducting wire technology that is useful at liquid nitrogen temperatures have significant circumstance for global development. That began the unprecedented progress in the creation of long biaxially textured coated conductors in high-tech industry $[16,17]$.
Presently, this technology has focused on epitaxial thin films deposited on biaxially textured $\mathrm{Ni}$ or Ni-based alloy substrates [18]. Unfortunately, many nickel alloys are ferromagnetic materials, what provide to potential limitations related to ferromagnetic hysteretic losses in the substrate [19]. The use of diamagnetic $\mathrm{Cu}$ tapes as the base metal substrate avoids those limitations. However, an apparent difficulty with copper is the oxidation of the metal surface [4]. The oxidation of $\mathrm{Cu}$ proceeds rapidly even at minimal oxygen partial pressure [20-22]. The crucial issue is not only oxidation of the substrate surface, but also diffusion of copper into the other layers [23]. The formation of a metal/ nonmetal heteroepitaxial multilayer is indispensable, because the grain boundaries are fast diffusion paths, although deposition of any films is such complex system presents additional challenges [24-26]. To address the need to suppress diffusion of both oxygen and copper, the epitaxial growth of $\mathrm{MgO} / \mathrm{TiN}$ on $\mathrm{Cu}$ was proposed firstly in 2003 by Cantoni and co-workers [5]. Magnesium oxide is an excellent barrier to oxygen diffusion. Titanium nitride have the lattice constant similar to $\mathrm{MgO}$, while at the same time exhibiting a high resistance to copper diffusion [10]. However, issue with a detrimental decomposition of titanium nitride in high oxygen partial pressure was reported $[5,8,10]$. Titanium nitride has the high tendency to decompose on nitrogen gas and titanium oxide. Unfortunately, the reaction of TiN films with oxygen is thermodynamically favorable, and the fast oxidation will occur when temperature is higher than $400^{\circ} \mathrm{C}$ [27]. Additionally, Cantoni [5,8] reported that heteroepitaxial titanium nitride film is able to significantly improve

* AGH UNIVERSITY OF SCIENCE AND TECHNOLOGY, FACULTY OF METALS ENGINEERING AND INDUSTRIAL COMPUTER SCIENCE, AL. A. MICKIEWICZA 30, 30-059 KRAKOW, POLAND

** AGH UNIVERSITY OF SCIENCE AND TECHNOLOGY, ACADEMIC CENTRE FOR MATERIALS AND NANOTECHNOLOGY, AL. A. MICKIEWICZA 30, 30-059 KRAKOW, POLAND

\# Corresponding author: gj@@agh.edu.pl 
in-plane alignment. It was unique, due to commonly reports about improvements in the out-of-plane texture of thin films as compared to metal substrate. However, the origin of this enhancement is still unclear. As was found [5], the TiN/Cu interface has been wavy and rough, but even then diffusion of copper had been suppressed. Such roughness likely originates at the $\mathrm{Cu}$ film surface and is retained in the growing TiN film. For this reason, the copper tapes surface preparation is very significant step [28,29]. Cantoni [5] connected this phenomena with roughening of the TiN film, which could be result from the disparity of titanium nitride thermal expansion compared with copper. Lu et al. $[12,30]$ results show that the surface of the copper tape at high temperature change with the cooling rate after graphene growth and its structure is also affected by the presence of graphene. They confirmed that different thermal coefficient could lead to generation of compressive stress during cooling. Consequently, depending on the substrate temperature and cooling rate, the direction of thin film growth can be different. Moreover, the copper grains oxidized at ambient conditions through the graphene grain boundaries and this same phenomena should occur onto TiN/Cu interface. The oxidation rate has been depended on the nature of interaction of the graphene layer with the $\mathrm{Cu}$. Such comprehensive research of TiN/Cu interface was not never done before. Hitherto, the influence of titanium nitride interaction with copper during and after deposition as well as present of misfit dislocations on the thin film growth and diffusion process is not known, as was for example previously presented for the $\mathrm{Cu} / \mathrm{TiN} / \mathrm{Si}, \mathrm{Cu} / \mathrm{MgO} / \mathrm{TiN} / \mathrm{Si}$ or CVD-grown graphene/Cu systems $[12,31,32]$.

\section{Experimental}

The copper tapes were prepared by cold rolling of commercial flat bar (99.9\% purity), $5 \mathrm{~mm}$ in thickness and final wide of the tape was $10 \mathrm{~mm}$. Before the rolling, the bar has been recrystallized via heating at $250^{\circ} \mathrm{C}$ at $30 \mathrm{~min}$. Afterwards, copper bar was rolled down at room temperature to $50 \mu \mathrm{m}$ thicknesses at small pass reductions until a deformation of $99 \%$ was achieved. The tapes were annealed in a vacuum furnace $\left(10^{-7}\right.$ Torr $)$ at $1 \mathrm{~h}$ for recrystallization and formation of cube texture. The TiN films were grown by means of the pulsed laser deposition (PLD) onto flexible copper tape, using the $248 \mathrm{~nm}$ excimer laser system (Coherent COMPexPro 110F) operated at an energy density of $\sim 3 \mathrm{~J} \mathrm{~cm}^{-2}$, a pulse width of $20 \mathrm{~ns}$, and a repetition rate of $10 \mathrm{~Hz}$. The target was stoichiometric titanium nitride (99.9\% purity) in form of ceramic disk (Able Target Limited, China) with 1 inch in diameter and $0.5 \mathrm{~cm}$ in thickness. The copper substrates were ultrasonically cleaned with acetone and methanol for $10 \mathrm{~min}$. Prior deposition of thin film, removal of copper oxide with hydrochloric acid (1:2 and 1:5 water-to-acid proportion) was performed at room temperature (so-called pre-treatment procedure). Post-acid exposed copper surface was not rinsed with DI water, but only dried with a nitrogen gas flow. After that, it was transferred to the high-vacuum chamber, immediately. The substrates were placed parallel to the target surface at a distance of $5 \mathrm{~cm}$, and later the deposition chamber was initially evacuated to $5 \times 10^{-7}$ Torr. The deposition temperature for the copper tapes were $400-600^{\circ} \mathrm{C}$ and deposition process occured in a nitrogen background pressure of $5 \times 10^{-6}$ Torr. The substrate cooling step with rate fixed for all sample at $15^{\circ} \mathrm{C} / \mathrm{min}$ has been performed.

After the deposition, the thin films was investigated using X-ray diffractional $\theta / 2 \theta$ scan (XRD, Panalytical Empyrean DY $1061)$, providing information on the phase composition and out-of-plane orientation. The X-ray diffraction experiments was carried out with using the $\mathrm{Cu}_{\mathrm{K} \alpha}$ radiation $(1.54 \AA$ ), and a nickel filter. The morphology and topography of surface were investigated with the scanning electron microscope (SEM, FEI Inspect S50) as well as the atomic force microscopy (AFM, Veeco Dimension ${ }^{\circledR}$ Icon ${ }^{\text {TM }}$ SPM) using tapping mode with amplitude modulation. The nature of epitaxy in these films was also studied using a cross-section samples in the $200 \mathrm{keV}$ high-resolution transmission electron microscope (HRTEM, FEI Tecnai TF 20 $\mathrm{X}$-TWIN) with point-to-point resolution of $0.25 \mathrm{~nm}$ and highangle annular dark field (HAADF) detector in STEM mode. The thin foils were cutted out with focused-ion beam device (FIB, FEI Quanta 3D 200i) equipped with OmniProbe lift-out system. The thin films surface was covered by platinum mask with an additional carbon layer as protection during FIB preparation.

\section{Results}

Figure 1 presents a (111) pole figure for a cube-textured $\mathrm{Cu}(99,9 \%)$ tape produced by cold rolling to $99 \%$ deformation followed by recrystallization at $800^{\circ} \mathrm{C}$ for $1 \mathrm{~h}$. The (111) peak positions indicate the existance of only the $\{100\}<001>$ cube orientation. Typical grains sizes are in the range of 80-120 $\mu \mathrm{m}$. Recrystallized tapes have root-mean-square (RMS) surface roughness of $17 \mathrm{~nm}$, determined using an atomic force microscope.

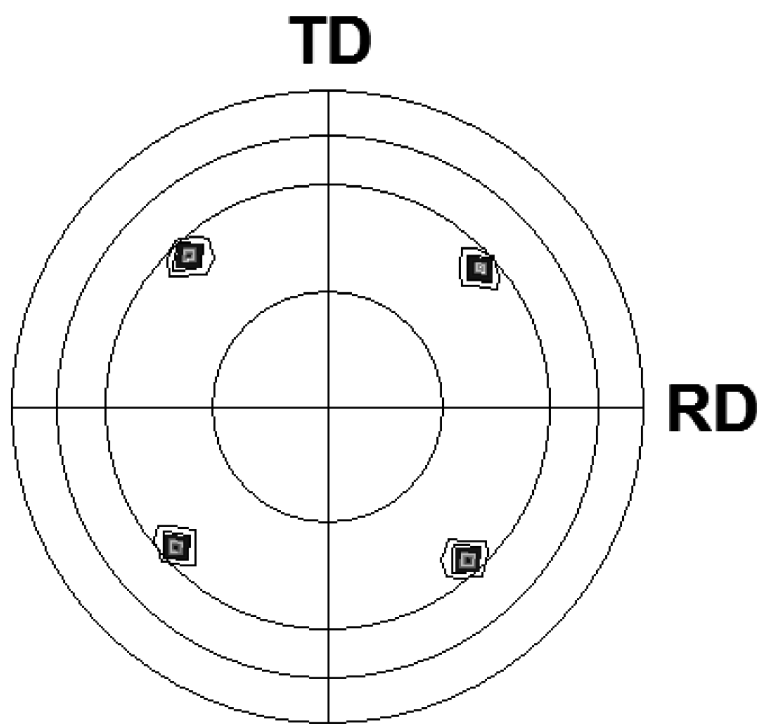

Fig. 1. (111) X-Ray pole figure for a rolled and a recrystallized $\mathrm{Cu}$ tape ( $\mathrm{TD}$ - traverse direction, $\mathrm{RD}$ - rolling direction) 
After deposition the colour of surface of copper have became lustreless gold. The morphology of the TiN/Cu film as well as $\mathrm{Cu}$ tape is shown in the scanning electron microscopy micrograph of Figure 2.

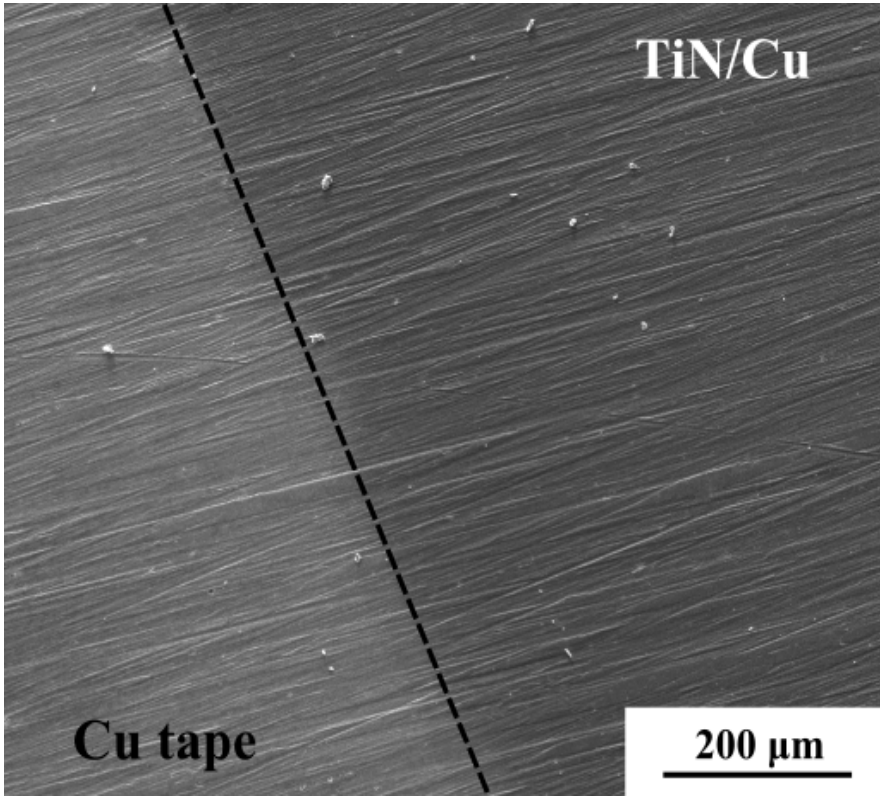

Fig. 2. SEM micrograph of a $\mathrm{Cu}$ tape (left side) and a TiN thin film (right side) deposited onto the cube-textured $\mathrm{Cu}$ substrate. The bright particles on the $\mathrm{Cu}$ tape as well as on the TiN thin film surface are contamination from air
Titanium nitride film reproduces exactly topography of the copper substrate. The micrograph reveals existence of typical linear rolling marks. As was previously observed by Cantoni [5], in as-rolled copper tapes the deep and round pits can exist. Those pits are the result of impurities present on the $\mathrm{Cu}$ tape during the rolling (such as oxides, etc.). Surprisingly, the very low amount of bright and large particles on thin films surface were observed. It is always challenging for pulsed-laser deposited films to achieve a droplet-free surface [33]. The origin of those surface contaminations are air and others environment sources. At this point it should be mentioned that the roughness measurements were tricky to performed, because the very elaborate and wavy surface of copper tapes have been occurred. The AFM surface analysis revealed presence of two main types of topography (Fig. 3).

First one was composed with elongated, flat grains and deep slips, which have formed a terraces-and-steps-like structure, which resemble the surface of the copper tape surface. Such structure have been dominating in samples etched by $\mathrm{HCl}$ 1:5 (Figs. 3a-c). The roughness of this structure was much higher than cube-textured tape (Table 1). However, the value of RMS was decreasing when substrate temperature was increasing. Second topography was aglomerated packages of TiN particles, typical structure for samples etched by $\mathrm{HCl}$ 1:2 (Figs. 3d-f). The passages between the pathways were very smooth and the nitride seems to filled them full. The smoothness of these thin films was much better than cube-textured tape and samples with $\operatorname{TiN}(200)$ thin film (Table 1).
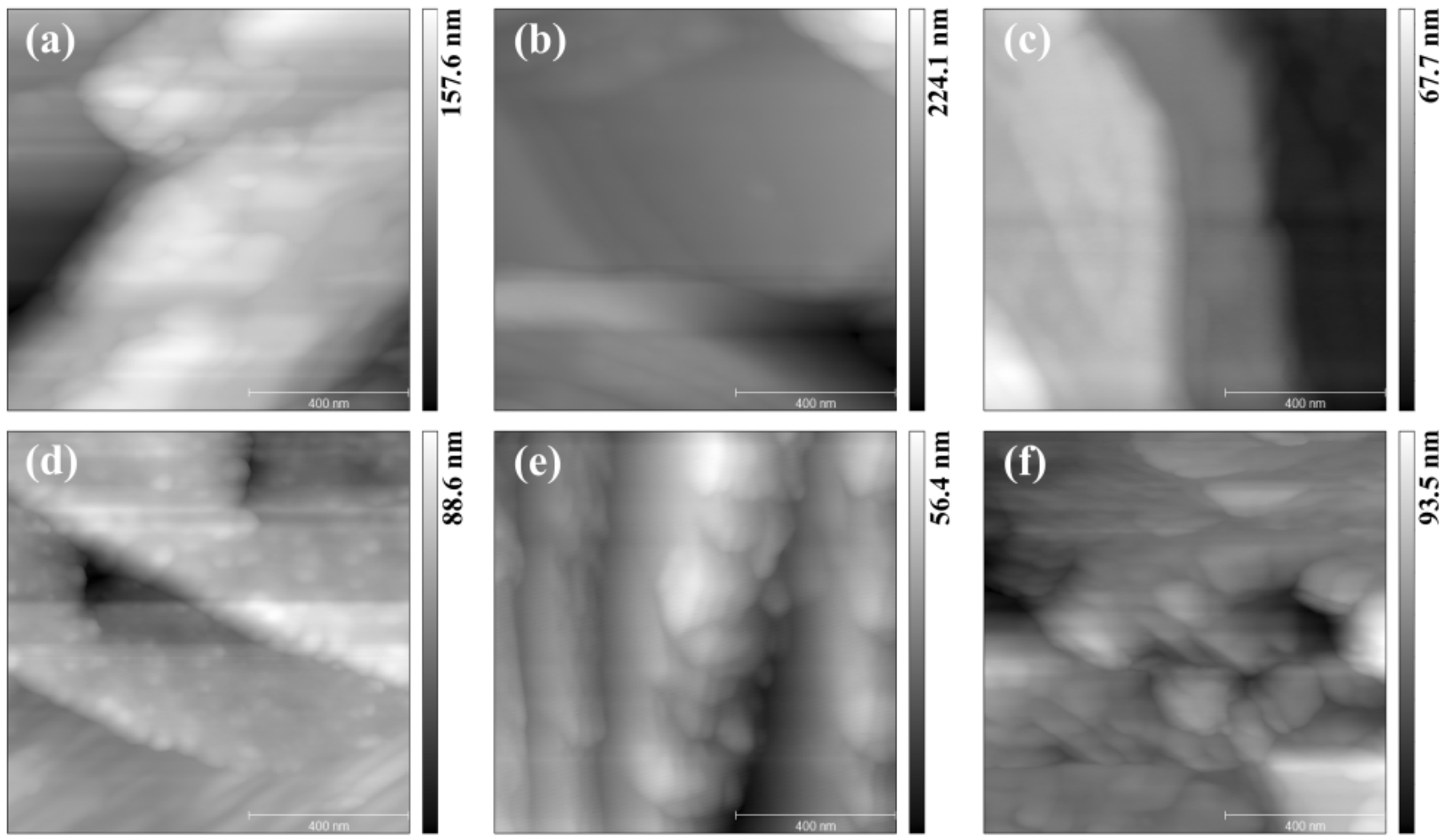

Fig. 3. Typical atomic force micrographs (3-D views, $1 \times 1 \mu \mathrm{m}^{2}$ ) of the TiN thin films after pre-treatment in $\mathrm{HCl} 1: 5$ and deposited at (a) $400^{\circ} \mathrm{C}$, (b) $500^{\circ} \mathrm{C}$ and (c) $600^{\circ} \mathrm{C}$ as well as after pre-treatment in $\mathrm{HCl} 1: 2$ and deposited at (d) $400^{\circ} \mathrm{C}$, (e) $500^{\circ} \mathrm{C}$ and (f) $600^{\circ} \mathrm{C}$. Note the use of different scale bars 
TABLE 1

RMS measurements results obtained for cube-textured copper tape as well as TiN(200)- and TiN(111)-oriented thin films

\begin{tabular}{|c|c|}
\hline Sample & $\boldsymbol{R}_{\boldsymbol{q}} / \mathbf{R M S}$ [nm] \\
\hline $\mathrm{Cu}\{100\}<001>$ & 17 \\
\hline $\operatorname{TiN}\left(\mathrm{HCl}(1: 5), 400^{\circ} \mathrm{C}\right)$ & 26 \\
\hline $\operatorname{TiN}\left(\mathrm{HCl}(1: 5), 500^{\circ} \mathrm{C}\right)$ & 19 \\
\hline $\operatorname{TiN}\left(\mathrm{HCl}(1: 5), 600^{\circ} \mathrm{C}\right)$ & 16 \\
\hline $\operatorname{TiN}\left(\mathrm{HCl}(1: 2), 400^{\circ} \mathrm{C}\right)$ & 11 \\
\hline $\operatorname{TiN}\left(\mathrm{HCl}(1: 2), 500^{\circ} \mathrm{C}\right)$ & 12 \\
\hline $\operatorname{TiN}\left(\mathrm{HCl}(1: 2), 600^{\circ} \mathrm{C}\right)$ & 14 \\
\hline
\end{tabular}

The X-Ray diffraction patterns (Figs. 4a-c) obtained from $\mathrm{TiN} / \mathrm{Cu}$ thin films (acid-etched by $\mathrm{HCl} 1: 5$ ) show that the presence of the same sets of lines, which can be matched with $\mathrm{TiN}(200)$ and $\mathrm{Cu}(200)$ peaks. Moreover, the increasing of intensity of this peak, when substrate temperature increased is indisputable. The TiN(111) peak have not been observed, notwithstanding, it may appear even in good quality of copper-based coated conductors [10].

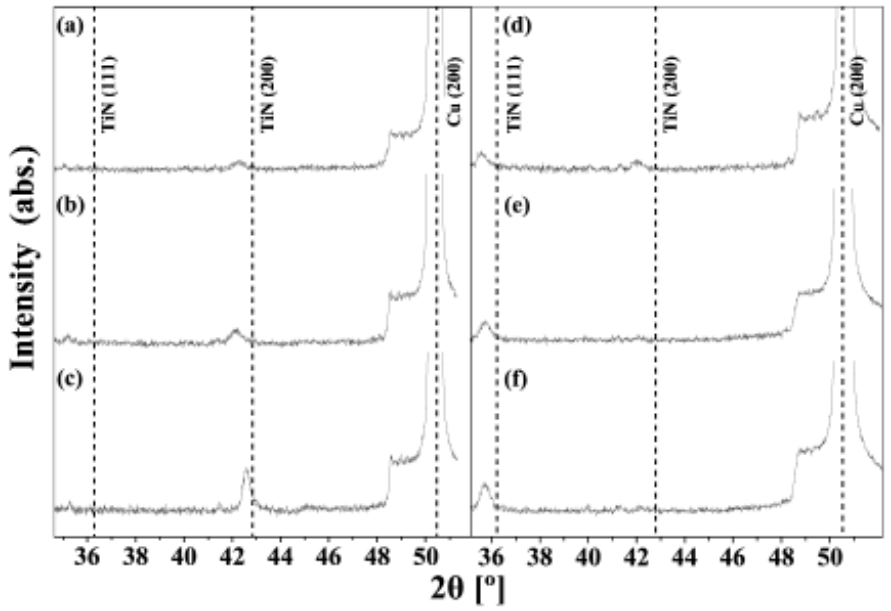

Fig. 4. X-ray diffraction for the TiN on cube-textured $\mathrm{Cu}$ tape deposited with different pre-treatment procedure and on variable substrate temperatures. The $\mathrm{HCl}$ 1:5 acid-etched tapes with TiN thin films deposited at substrate temperatures (a) $400^{\circ} \mathrm{C}$, (b) $500^{\circ} \mathrm{C}$, (c) $600^{\circ} \mathrm{C}$ as well as the $\mathrm{HCl} \mathrm{1:2} \mathrm{acid-etched} \mathrm{tapes} \mathrm{with} \mathrm{TiN} \mathrm{thin} \mathrm{films} \mathrm{deposited} \mathrm{at} \mathrm{substrate}$ temperatures (d) $400^{\circ} \mathrm{C}$, (e) $500^{\circ} \mathrm{C}$, (f) $600^{\circ} \mathrm{C}$

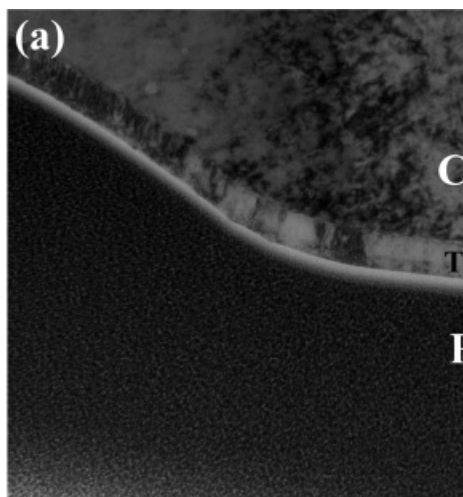

(c)

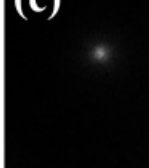

$\cdot$
$+\quad 00 \overline{2}$

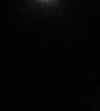

$\bullet$

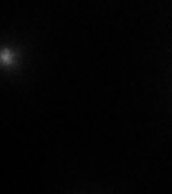

$*$

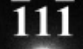

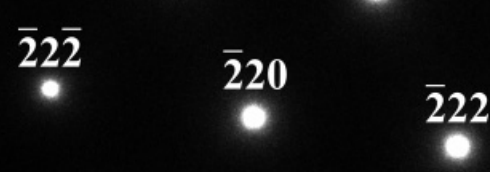

$\overline{222}$

Pt

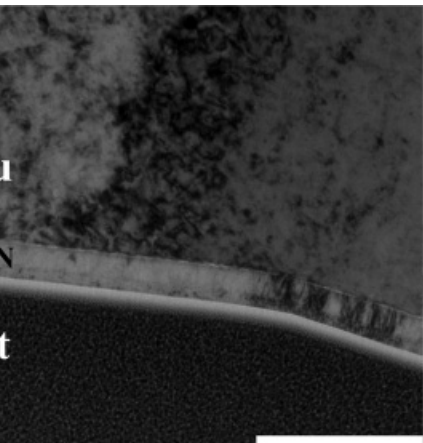

$200 \mathrm{~nm}$

$\bullet$

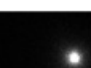

(b)

$\mathrm{Cu}$

TiN

Pt

\section{(d)}

$200 \mathrm{~nm}$

$2 \overline{2} 2$
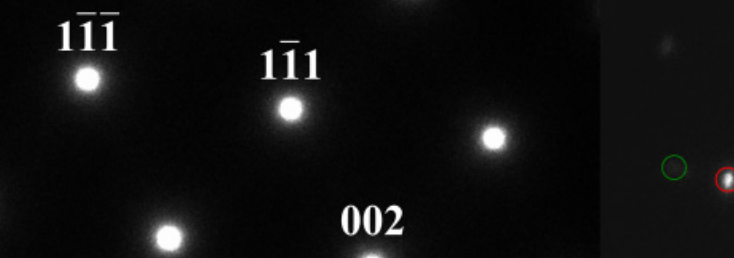

- $\mathrm{Cu}(00)^{2}$

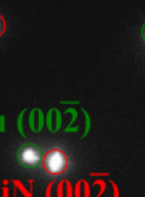

$\therefore$
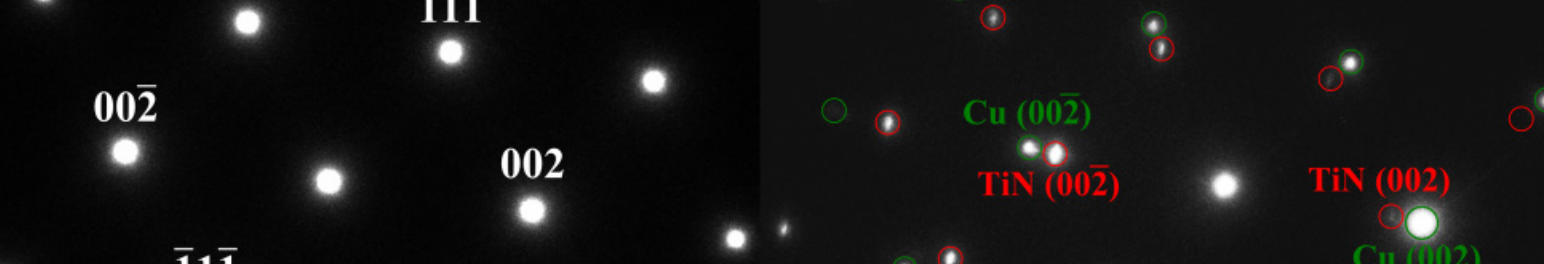

$\overline{1} 11$

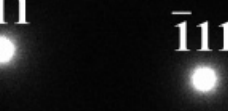

0

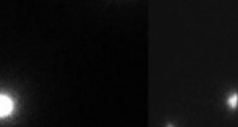

-
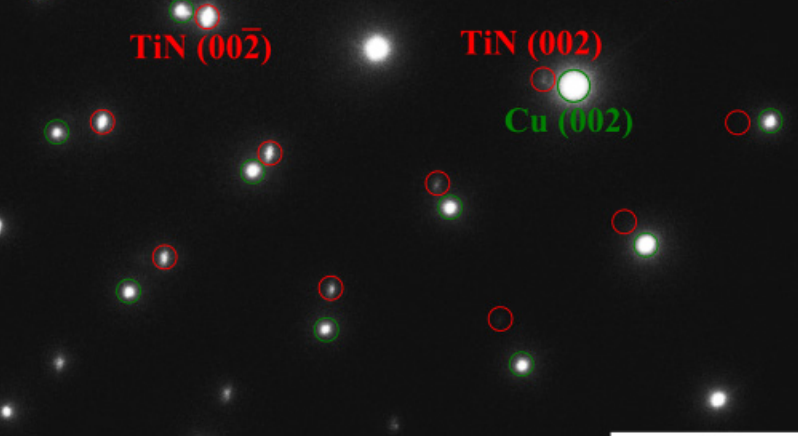

$51 / \mathrm{nm}$

Fig. 5. (a) The typical cross-sectional BF TEM image and (b) STEM image acquired with HAADF detector of a $\operatorname{TiN}(200) / \mathrm{Cu}\{100\}<001>$ thin film. (c) The [110] zone-axis SAED pattern of $\mathrm{Cu}\{100\}<001>$ tape. (d) The [110] zone-axis SAED pattern of a $\operatorname{TiN}(200) / \mathrm{Cu}\{100\}<001>$ thin film, in which the diffraction patterns spots corresponding to TiN (red) and $\mathrm{Cu}$ (green) are labelled 
Contrary to that, in TiN/Cu thin films (acid-etched by $\mathrm{HCl}$ 1:2) the present of TiN(111) peak have been observed. The intensity of this peak is also changing with increasing of substrate temperature. The TiN(200) peak is absent in those diffraction patterns except the unsettling peak which appeared for low-temperature deposited thin film (Fig. 4d). In both cases, the increasing of peaks intensity can be connected with improvement of crystallity and density of thin films. No evidence of additional phases or interfacial reaction products was observed in the XRD patterns. The TiN thin films deposited onto $\mathrm{HCl}$ 1:5 acid-etched tapes have demonstrated the preferential orientation (h00), normal to the $\mathrm{Cu}(200)$ substrate, suggesting the heteroepitaxial growth. The out-of-plane lattice parameters of samples are smaller than that (4.24 $\AA$ ) of bulk TiN [10] and the position of TiN(200) as well as TiN(111) peaks is shifting to the lower angles with function of substrate temperature. This shift was smaller if TiN thin films have been deposited on higher temperature.

The crystalline quality and epitaxial orientation relationship of the pulsed-laser deposited TiN films were also investigated using HRTEM. Figure 5a shows the typical cross-sectional bright field (BF) TEM image of $\operatorname{TiN}(200) / \mathrm{Cu}\{100\}<001>$ deposited at $600^{\circ} \mathrm{C}$.

The platinum and graphite layers were deposited onto foil for protection during the FIB sample preparation process. The thickness of TiN thin films are estimated to be $\sim 75 \mathrm{~nm}$. All thin films are uniform and continuous, moreover, even on the waviness, the thickness and continuous of thin films have been preserved (Figs. 5a,b). Figure 5b shows a low-magnification Z-contrast image of the $\mathrm{TiN}(200)$ thin film grown on the $\mathrm{Cu}$ substrate $\left(600^{\circ} \mathrm{C}\right)$. The interface shown appear clean and there is no evidence of detrimental reactions or interdiffusion between the thin film and substrate. However, the observation of $\mathrm{BF}$ and HAADF images revealed existence of second type of thin films structure, which have grown on $50 \mathrm{~nm}$ of heteroepitaxial $\operatorname{TiN}(200)$ film. Such structure seems be a fine-grained or a heavily defected TiN and their thickness can be estimete at $25 \mathrm{~nm}$. This effect is an artifact created by high-energy ion bombarding of the edge of lamella during FIB preparation. There is no evidence nor change of deposition parameter, which should confirmed the alteration of TiN growth during process. Besides, it is local effect, which occurred only in few places. The typical [110] zone axis selected-area electron diffraction (SAED) pattern of the cube-textured copper and $\operatorname{TiN}(200) / \mathrm{Cu}\{100\}<001>$ thin film is shown in Figs. 5c,d. In copper substrate the structural changes have not been observed. The alignment of $\mathrm{Cu}$ and TiN of diffraction spots for system deposited on $\mathrm{HCl}$ 1:5 acid-etched substrates proves the cube-on-cube epitaxial relationship.

\section{Discussion}

In this study, we have shown that the growth of TiN thin films deposited onto cube-textured copper-based tapes has been very sensitive to pre-treatment procedure and substrate temperature. Based on researches and findings obtained by
Piñol and co-workers [28] the cube-textured copper tapes have been prepared (Fig. 1). The sharp cube texturing $\{100\}<001>$ is parallel to the rolling direction (RD) of the tape. The copper tape always is covered by native oxide $\left(\mathrm{Cu}_{2} \mathrm{O}, \mathrm{CuO}\right)[5,6,11,20]$ and few methods have been introduce for preventing $\mathrm{Cu}$ oxidation. The most important were focused on depositing metal layers $(\mathrm{Ni}$, Ir, etc.) [34,35], alloying chemical elements such as magnesium, chromium and aluminium that are known to be oxygen getters [36] or preparation of novel copper-based alloys [37-40]. Unfortunately, most of them were led to increasing of the resistivity of copper, deterring the use of that alloy as the RABiTS's substrate material. Besides, the copper oxidation is not only problem in RABiTS technology and the significant approaches have been performed in fields like electrochemistry $[22,41,42]$ or deposition of CVD-grown graphene [11,12], either. The most effective methods of in situ stripping of copper oxide contain a low-energy ion-beam cleaning [5] and an annealling in hydrogen reducing atmosphere at $1000^{\circ} \mathrm{C}$ [11]. Unfortunately, both approaches have require using of advanced equipments. The much easier way is chemical wet etching. The some solutions can either etch only copper oxide or copper, as well. However, as today non mixture has been found, which could be such effective like HF acid for silicon substrates, where the passivation effect preventing of surface oxidation has appeared [43]. At most, the copper oxide layer can be limited to few nanometers, however, always will regrowth before deposition process [5]. Whether, we have decided to etch copper-based tapes surface by diluted $\mathrm{HCl}$ acid in different proportions. Hydrochloric acid can etch both copper oxides, but $\mathrm{Cu}$ atoms are only removed at the kinks in the [010] and [001] steps [44]. In our experiment we have used titanium nitride possession to reduce oxide layer due to its high affinity to oxygen, which in result should provide to achieve pure titanium nitride-copper interface. It is worth noting that, respectively, the $\mathrm{Cu}_{2} \mathrm{O}(200)$ and $\mathrm{Cu}_{2} \mathrm{O}(111)$ peaks can not be discriminated with $\mathrm{TiN}(200)$ and TiN(111) peaks, because on XRD pattern their positions are overlapping [45]. Such assumption has been affirmed in our case (Figs. 5a,b), where clear TiN/Cu interface was observed. Indeed, titanium nitride can reduce the residual amount of copper oxides, as more, it can successfully protect copper surface against oxidation after deposition. The HAADF image (Fig. 5b) accurately revealed that chemical composition of thin film is uniform as well as the interface between copper and titanium nitride is sharp. The intermixing zone have not been observed. However, the $\mathrm{TiN}(200) / \mathrm{Cu}$ interface have waviness morphology with clearly observed valleys, directed parallel to tape surface, remained after rolling process. The roughness of copper tape has retained in the growing TiN film, as suggested by atomic force microscopy (AFM) analysis (Table 1). Nonetheless, the TiN(111) films have much better RMS value than copper substrate and even TiN(200) films. We believe, it was possible because the (111)-oriented grains had a much bigger possibility to accommodate the misfit and the strain during growth.

The variation of integrated intensities of (200) and (111) peaks for the TiN films deposited on $\mathrm{Cu}\{100\}<001>$ substrate is found to be a strong function of substrate temperature (Fig. 4). 
The incremental increasing of intensity of TiN(200) and TiN(111) diffraction lines were observed for the films deposited at whole substrate temperature range $\left(400-600^{\circ} \mathrm{C}\right)$. In case of $\operatorname{TiN}(200)$ peak is indicating that the films are highly aligned along the direction normal to the substrate plane (cube-on-cube epitaxy). The position of the $\mathrm{TiN}(200)$ and $\mathrm{TiN}(111)$ peaks is shifted to the lower angles. Owing to huge difference in thermal expansion coefficient among copper and titanium nitride (48\%) [5] and lattice parameters $(17 \%)$, the out-of-plane compressive and inplane tensile stresses should occurred. The shift is smaller for thin films deposited at higher substrate temperature, what suggested that the origin of stress have contained in defects created during deposition, and partly annihilated within cooling stage. Indeed, the low-angle annular dark-field analysis showed that TiN film is the most defective buffer layer in $\mathrm{Cu}$-based coated conductors architecture [5]. The misfit of over $17 \%$ for cube-on-cube relationship of TiN $(\mathrm{a}=0.424 \mathrm{~nm})$ with the underlying copper $(\mathrm{a}=0.361$ $\mathrm{nm}$ ), it is beyond the critical strain of conventional lattice matching (LME). Fortunately, epitaxial growth of $\operatorname{TiN}(200) \| \mathrm{Cu}\{100\}<001>$ can be described by the concept of domain-matching epitaxy (DME) [46]. We calculated that TiN films should grows on $\mathrm{Cu}$ with alternating 5/6 and 6/7 domain matching mechanisms, and each domains are separated by misfit dislocation. However, nature of this epitaxy is very sensitive to thermal misfit strain, which means that the bigger aberration could be observed for system with significant difference in thermal expansion coefficient. Moreover, as far as we know the correction of DME have not been verified for polycrystalline substrates [47]. We supposed that in case of cube-textured copper, on each single copper grain the heteroepitaxial TiN film will separately growth according to DME paradigm. Hence, the study of influence of copper grains size onto TiN thin films growth should be perform in future.

The pre-treatment procedure have significant influence on thin films growth direction as well as peaks positions, either. The direction of TiN films growth have been changed by application of different etcher. Hydrochloric acid diluted in proportion 1:5 with water allowed TiN(200) growth (Figs. 4a-c). On the other hand, hydrochloric acid diluted in 1:2 proportion with water induced the growth in direction (111) (Figs. 4d-f). As was recently reported, Oh and Je [48] showed that the preferred orientation of TiN film is ruled through the competition between the surface energy and the strain energy. More clearly the competing planes in the TiN film are (200) with the lowest surface energy and (111) with the lowest strain energy. In our cases, the $\mathrm{HCl} 1: 2$ have etched the copper oxides as well as reduced the residual strain in substrate before the deposition. On the such surface, the TiN(111) was promoted due to high activiation. This is the most simple explaination why TiN(200) peak have appeared for low-temperature deposited thin film onto $\mathrm{HCl} \mathrm{1:2} \mathrm{etched} \mathrm{Cu}$ tape (Fig. 4d). However, RMS measurements (Table 1) clearly showed that both $\mathrm{HCl}$ 1:2 have not roughen and uneven the copper tapes surface and roughness can not be cause which single-handedly affect on the growth direction. The tapes with TiN(200) should be much smoother than substrate with TiN(111) thin films. That is why, we have decided to use growth model firstly proposed for
TiN films sputtered onto single-crystal silicon [49]. All titanium nitride thin films have grown in (200) direction onto individual copper grains and at beginning those seeds did not contact with each others. (200)-oriented grain was grown by completing the energetically favorable (200) planes in the initial stage, due to significant surface energy or the co-growth in both direction have occurred simultaneously. Later, the growth direction could changed to (111) for thin films deposited onto $\mathrm{HCl}$ 1:2 acid-etched copper, due to existence of strain. It is worth noting that changing of strain in grains during the growth is common [49]. The increasing of substrate temperature have promoted the change of growth direction and reduced the amount of TiN(200) grains. Contrary to that the $\mathrm{TiN}(200)$ grains can growth together with (111)-oriented grains during whole deposition process. The primary or residual (200)-oriented grains detected on X-Ray diffraction pattern of low-temperature deposited TiN film (Fig. 4d) seems confirm these two models. We believe it was possible, because underlying copper oxide layer was different for each pretreatment procedure. Unfortunately, there is couple of equivalent explanations. In many cases, in air on the surface of copper the duplex structure of copper(II) oxide and copper(I) oxide can form [42]. However, in partial pressure of oxygen in our deposition, the formation of copper oxides is different and more complicated. Up to $600^{\circ} \mathrm{C}$, the oxidation process should be the same like in air, but much slower due to depletion of oxygen atoms. At temperature close to $600^{\circ} \mathrm{C}$ and partial pressure at $10^{-6}$ Torr, the formation of only $\mathrm{Cu}_{2} \mathrm{O}$ should occurred [9,50]. Unfortunately, this have not influence on growth direction, because $\mathrm{TiN}(200)-$ oriented grains can be observed even at $400^{\circ} \mathrm{C}$. The time for oxidation after stripping of native copper oxides was very short and equal for every samples at the same substrate temperature. After all, the heating speed was constant, but even then the time of oxidation for sample heated to higher temperature was insignificantly longer. Wherefore, we can assume that regrown copper oxide have nearly the same thickness as well as chemical composition $\left(\mathrm{Cu}_{2} \mathrm{O}\right)$ [51]. Cuprous oxide have face-centered cubic lattice with parameter $\mathrm{a}=0.427 \mathrm{~nm}$ [52], which is similar to lattice constant of TiN. Nonetheless, they have a different space groups. For such affair, titanium nitride could replicated the growth direction of cuprous oxide, which naturally growth epitaxially onto copper oxide, before the reduction occurred. Further, the cuprous oxide growth for $\mathrm{HCl}$ 1:2 acid-etched tape may have been disturbed. Such disorder seems be bigger, when substrate temperature have increased, what led to formation of TiN(111) grains. It is much more advantaged situation, because oxides of metals do not generally adopt the lattice constant of the substrate metal [51]. The X-Ray diffraction patterns (Figs. 4d,e,f) suggested that out-of-plane compressive stress is much larger for samples with (111)-oriented grains and only slightly depended on substrate temperature. This and evidence of smoother surface have confirmed that (111)-oriented grains were less defective than TiN(200). Surprisingly, the small amount of heteroepitaxial cuprous oxide at the beginning of the deposition can helps obtain the well oriented TiN(200) grains. This theory can be completely verify only by using in situ and real-time techniques such as 
low-energy and reflection high-energy electron diffractions, which allow observed the changes onto surface of crystalline materials during deposition. What is more, that phenomena should appeared for single-crystal copper, as well.

The [110] zone-axis selected area diffraction pattern (Fig. 5d) obtained at $\mathrm{TiN}(200) / \mathrm{Cu}$ interface revealed that between thin film and substrate exists cube-on-cube relationship. The bright spots on electron diffraction pattern corresponding to TiN and $\mathrm{Cu}$ are labeled. Any additional spots which origin could be connected to interfacial reaction have not been observed. The diffraction points corresponding to the same planes of TiN and $\mathrm{Cu}$ split, but appear along the same crystallographic directions, due to the differences of lattice parameters. Thus, the overlapping of spots did not occurred, even when the out-of-plane compression stress remained in system. Additionaly, the XRD as well SAED patterns concordantly showed that lattice parameter in out-ofplane direction have insignificantly decreased. The comparison of SAED pattern of cube-textured copper with and without thin film (Fig. 5c) shows that there is no difference between them. Hence, the structural nature of copper substrate has not been affected through deposition process. That is utterly different that was showed for CVD-grown graphene films [11]. Presumably, the source of this difference is substrate temperature. In our cases this parameter was relatively low, where for graphene the substrate temperature always is close to melting point of copper.

One of the major differences between the TiN thin films deposited onto $\mathrm{HCl} 1: 2$ and $\mathrm{HCl}$ 1:5 acid-etched tapes is the morphology of the film surface. Samples with TiN(200)-oriented grain have exhibited a much rougher surface than pure copper tape and (111)-oriented films (Table 1). However, the roughness of all thin films have decreased, when substrate temperature has increased.Generally, during any heat treatment or growth of thin films, surface diffusion along the film surface is the dominant mechanism of mass transport [53]. Hence, the thermal activation of atoms onto surface during deposition have triggered a smoothness of thin films surfaces. Otherwise, the difference in surface morphology and RMS measurements for two types of thin films is puzzling. We do not believe it was possible, due to changes occuring in copper tape during deposition. Unambiguous explanation of mechanism appearing during thin films growth and having influence on the roughness required preparing films onto single-crystal copper. For example, the TiN thin films deposited onto single-crystal silicon with (111) planes, if were nucleated locally, had smooth surface. Contrary to that, the (200) planes have formed rough hills-valleys morphology [49]. In our case for TiN(200)-oriented grain, we have obtained a terraces-andsteps-like morphology (Figs. 3a-c). Those type of morphology is characterised by existence of flat grains seperated via very sharp slips. As was aforementioned, the TiN(200)-oriented grains grown were uniform and deposited materials seem to completely fill all inequalities, which were created during rolling process. Contrary, surface analysis performed on TiN(111)-oriented grains (Figs. 3d-f) suggested that meaningful agglomeration occurred. The AFM images revealed existence of oval particles packages, which size is increased with substrate temperature.
The surface morphology of TiN(200)- and TiN(111)-oriented grains is different. Despite, the comprehensive research with cross-section analysis as well as plain-in-view observation shall be performed for TiN(111)-oriented grains. As was recently reported, the surface energy among copper and titanium nitride is high. Furthermore, at all deposition temperatures the growth of copper thin film on $\mathrm{TiN}(200) / \mathrm{Si}(100)$ system was found to be island type (3-D) [31]. Instead, we and other group [5,10] clearly showed that growth of (200)-oriented titanium nitride thin film on polycrystalline copper is totally different. However, the nature of TiN(111) growth onto copper tape must be recognise, because the present data suggest that (111)-oriented grains could growth much more similarly to copper thin film onto TiN buffer layer than $\operatorname{TiN}(200)$ thin film on copper tape.

\section{Conclusions}

In the summary, the TiN thin films were fabricated onto cube-textured copper tapes with evaluation of influence of substrate temperature and pre-treatment procedure. The XRD and TEM results revealed that the TiN uniform and continous film grow epitaxially with relationship $<200>\mathrm{TiN} \|<200>\mathrm{Cu}$ (cube-on-cube epitaxy). No interfacial reactions between $\mathrm{Cu}$ and TiN were observed up to $600^{\circ} \mathrm{C}$. The pre-treament procedure with $\mathrm{HCl}$ 1:5 allowed growth of well-oriented $\mathrm{TiN}(200)$ thin films, conversely, on the $\mathrm{HCl} 1: 2$ acid-etched copper tape the TiN(111)-oriented grains have grown. Both type of TiN thin films have been under compressive stress due to difference in lattice parameters between copper and titanium nitride. The change of surface morphology of TiN thin films have depended on films orientation. The relatively thin layer $(\sim 75 \mathrm{~nm})$ have suppress the copper diffusion as well as copper oxidation have not occurred. However, in the future, more successful coated conductor architectures could involve different metal substrates and/or different buffer materials than those used today.

\section{Acknowledgments}

This work was supported by the AGH University of Science and Technology under Grant No. 15.11.110.349. The authors thank J. Kusiński (AGH University of Science and Technology) for discussions and for his helpful suggestions regarding TEM and SAED pattern image analyses. The technical assistance from The Nanostructures and Nanodevices Research Line of Academic Centre for Materials and Nanotechnology AGH is also acknowledged.

\section{REFERENCES}

[1] J. Narayan, P. Tiwari, X. Chen, J. Singh, R. Chowdhury, T. Zheleva, Appl. Phys. Lett. 61, 1290 (1992).

[2] J.O. Olowolafe, C.J. Mogab, R.B. Gregory, M. Kottke, J. Appl. Phys. 72, 4099 (1992). 
[3] R.D. Vispute, J. Narayan, J. Electron. Mater. 25, 1740 (1996).

[4] T. Aytug, M. Paranthaman, J.R. Thompson, A. Goyal, N. Rutter, H.Y. Zhai, A.A. Gapud, A.O. Ijaduola, D.K. Christen, Appl. Phys. Lett. 83, 3963 (2003).

[5] C. Cantoni, D.K. Christen, M. Varela, J.R. Thompson, S.J. Pennycook, E.D. Specht, A. Goyal, J. Mater. Res. 18, 2387 (2003).

[6] C. Cantoni, D.K. Christen, E.D. Specht, M. Varela, J.R. Thompson, A. Goyal, C. Thieme, Y. Xu, S.J. Pennycook, Supercond. Sci. Technol. 17, S341 (2004).

[7] Y.X. Zhou, L. Sun, X. Chen, H. Fang, P.T. Putman, K. Salama, Supercond. Sci. Technol. 18, 107 (2004).

[8] C. Cantoni, A. Goyal, U. Schoop, X. Li, M.W. Rupich, C. Thieme, A.A. Gapud, T. Kodenkandath, T. Aytug, M. Paranthaman, K. Kim, J.D. Budai, D.K. Christen, IEEE Trans. Appl. Supercond. 15, 2981 (2005).

[9] K. Kim, M. Paranthaman, D.P. Norton, T. Aytug, C. Cantoni, A.A. Gapud, A. Goyal, D.K. Christen, Supercond. Sci. Technol. 19, R23 (2006).

[10] K.H. Kim, D.P. Norton, D.K. Christen, C. Cantoni, M. Paranthaman, T. Aytug, Vacuum 83, 897 (2009).

[11] C. Mattevi, H. Kim, M. Chhowalla, J. Mater. Chem. 21, 3324 (2011).

[12] A.Y. Lu, S.Y. Wei, C.Y. Wu, Y. Hernandez, T.Y. Chen, T.H. Liu, C.W. Pao, F.R. Chen, L.J. Li, Z.Y. Juang, RSC Adv. 2, 3008 (2012).

[13] D.P. Norton, A. Goyal, J.D. Budai, D.K. Christen, D.M. Kroeger, E.D. Specht, Q. He, B. Saffian, M. Paranthaman, C.E. Klabunde, D.F. Lee, B.C. Sales, F.A. List, Science 274, 755 (1996).

[14] D.P. Norton, D.H. Lowndes, J.D. Budai, D.K. Christen, E.C. Jones, K.W. Lay, J.E. Tkaczyk, Appl. Phys. Lett. 57, 1164 (1990).

[15] S. Kang, A. Goyal, J. Li, A.A. Gapud, P.M. Martin, L. Heatherly, J.R. Thompson, D.K. Christen, F.A. List, M. Paranthaman, D.F. Lee, Science 311, 1911 (2006).

[16] W. Goldacker, F. Grilli, E. Pardo, A. Kario, S.I. Schlachter, M. Vojenčiak, Supercond. Sci. Technol. 27, 093001 (2014).

[17] M.W. Rupich, U. Schoop, D.T. Verebelyi, C. Thieme, W. Zhang, X. Li, T. Kodenkandath, N. Nguyen, E. Siegal, D. Buczek, J. Lynch, M. Jowett, E. Thompson, J.S. Wang, J. Scudiere, A.P. Malozemoff, Q. Li, S. Annavarapu, S. Cui, L. Fritzemeier, B. Aldrich, C. Craven, F. Niu, R. Schwall, A. Goyal, M. Paranthaman, IEEE Trans, App. Supercond. 13, 2458 (2003).

[18] M.P. Paranthaman, T. Izumi, MRS Bull. 29, 533 (2004).

[19] A.O. Ijaduola, J.R. Thompson, A. Goyal, C.L.H. Thieme, K. Marken, Physica C 403, 163 (2004).

[20] P. Keil, D. Lützenkirchen-Hecht, R. Frahm, AIP Conf. Proc. 882, 490 (2007)

[21] J.W. Lim, J. Iijima, Y. Zhu, J.H. Yoo, G.S. Choi, K. Mimura, M. Isshiki, Thin Solid Films 516, 4040 (2008).

[22] K. Mech, R. Kowalik, P. Żabiński, Arch. Metall. Mater. 56, 903 (2011).

[23] A. Gupta, H. Wang, A. Kvit, G. Duscher, J. Narayan, J. Appl. Phys. 93, 5210 (2003).

[24] K. Mašek, S. Nemšák, V. Matolín, Vacuum 82, 274 (2007).

[25] H. Wang, X. Zhang, A. Gupta, A. Tiwari, J. Narayan, Appl. Phys. Lett. 83, 3072 (2003).
[26] J. Morgiel, T. Wierzchoń, Surf. Coat. Technol. 259, 473 (2014).

[27] K. Wu, P. Lin, C. Hsieh, S. Liu, J. Juang, T. Uen, J.Y. Lin, Y. Gou, Physica C 363, 119 (2001).

[28] S. Piñol, J. Díaz, M. Segarra, F. Espiell, Supercond. Sci. Technol. 14, 11 (2000).

[29] J. Díaz, M. Segarra, F. Espiell, S. Piñol, Supercond. Sci. Technol. 14, 576 (2001).

[30] S. Chen, L. Brown, M. Levendorf, W. Cai, S.Y. Ju, J. Edgeworth, X. Li, C.W. Magnuson, A. Velamakanni, R.D. Piner, J. Kang, J. Park, R.S. Ruoff, ACS Nano 5, 1321 (2011).

[31] R.D. Vispute, R. Chowdhury, P. Tiwari, J. Narayan, Appl. Phys. Lett. 65, 2565 (1994).

[32] F. Wu, J. Narayan, Cryst. Growth Des. 13, 5018 (2013).

[33] J. Kusinski, S. Kac, A. Kopia, A. Radziszewska, M. Rozmus-Górnikowska, B. Major, L. Major, J. Marczak, A. Lisiecki, Bull. Pol. Ac.: Tech. 60(4), 711 (2012).

[34] N.A. Rutter, A. Goyal, C.E. Vallet, F.A. List, D.F. Lee, L. Heatherly, D.M. Kroeger, Supercond. Sci. Technol. 17, 527 (2004).

[35] T. Aytug, M. Paranthaman, H.Y. Zhai, A.A. Gapud, K.J. Leonard, P.M. Martin, A. Goyal, J.R. Thompson, D.K. Christen, Appl. Phys. Lett. 85, 2887 (2004).

[36] W.A. Lanford, P.J. Ding, W. Wang, S. Hymes, S.P. Muraka, Thin Solid Films 262, 234 (1995).

[37] A. Girard, C.E. Bruzek, J.L. Jorda, L. Ortega, J.L. Soubeyroux, J. Phys. Conf. Ser. 43, 341 (2006).

[38] J.L. Soubeyroux, C.E. Bruzek, A. Girard, J.L. Jorda, IEEE Trans. Appl. Supercond. 15, 2687 (2005).

[39] C.V. Varanasi, L. Brunke, J. Burke, I. Maartense, N. Padmaja, H. Efstathiadis, A. Chaney, P.N. Barnes, Supercond. Sci. Technol. 19, 896 (2006).

[40] C.V. Varanasi, P.N. Barnes, N.A. Yust, Supercond. Sci. Technol. 19, 85 (2005).

[41] H. Ju, Y.H. Lee, Y.S. Lee, S.K. Rha, Journal of Surface Analysis 17(3), 287 (2011).

[42] A. Satta, D. Shamiryan, M.R. Baklanov, C.M. Whelan, Q.T. Le, G.P. Beyer, A. Vantomme, K. Maex, J. Electrochem. Soc. 150, G300 (2003).

[43] T. Takahagi, I. Nagai, A. Ishitani, H. Kuroda, Y. Nagasawa, J. Appl. Phys. 64, 3516 (1988).

[44] M.R. Vogt, A. Lachenwitzer, O.M. Magnussen, R.J. Behm, Surf. Sci. 49, 399 (1998).

[45] A.O. Musa, T. Akomolafe, M.J. Carter, Sol. Energy Mater. Sol. Cells 51, 305 (1998).

[46] J. Narayan, B.C. Larson, J. Appl. Phys. 93, 278 (2003).

[47] J. Narayan, Acta Mater. 61, 2703 (2013).

[48] U.C. Oh, J.H. Je, J. Appl. Phys. 74, 1692 (1993).

[49] J.H. Je, D.Y. Noh, H.K. Kim, K.S. Liang, J. Appl. Phys. 81, 6126 (1997).

[50] M.F. Al-Kuhaili, Vacuum 82, 623 (2008).

[51] C.L.H. Devlin, Y. Sato, S. Chiang, J. Appl. Phys. 105, 123534 (2009).

[52] K. Fujimoto, T. Oku, T. Akiyama, A. Suzuki, J. Phys. Conf. Ser. 433, 012024 (2013).

[53] H. Gao, W.D. Nix, Annu. Rev. Mater. Sci. 29, 173 (1999). 